\title{
The Cyberbullying Experiences Survey with New Zealand Psychology Students
}

Tracey Phizacklea and Rebecca J. Sargisson ${ }^{\star}$

School of Psychology, The University of Waikato, Private Bag 12027, Tauranga 3112, New Zealand

\begin{abstract}
Research suggests that cyberbullying continues during emerging adulthood, but is less often studied than with adolescent populations. We investigated the prevalence of cyberbullying behaviors amongst 312 New Zealand University psychology students using the Cyberbullying Experiences Survey. Most respondents reported experiencing (94.9\%) and perpetrating (82.0\%) some form of cyberbullying victimization in the past year, with men reporting higher rates than women. Men were also more likely to be both victims and perpetrators of cyberbullying. However, the criteria for having experienced cyberbullying of at least once in the last year may have been too lenient. The average scale score for victimization and perpetration suggested a fairly low prevalence of cyberbullying among our sample. Our findings supporting the reliability of the Cyberbullying Experiences Survey were consistent with previous research using similar methods. We suggest avenues for future research to explore the nature of cyberbullying among emerging adults.
\end{abstract}

\section{Introduction}

With continued advances in technology, traditional bullying can now occur through social media and mobile devices anywhere, at any time, reaching social networks quickly, and leaving evidence that can be nearly impossible to erase. Cyberbullying has been defined as "willful and repeated harm inflicted through the use of computers, cell phones and other electronic devices" [1] (pp5) and can be particularly vicious due to the real or imagined anonymity afforded by the internet [2].

University students are amongst the most frequent and technically advanced users of the internet and mobile devices globally [3]. A modest body of research suggests that cyberbullying continues, or even increases, through adolescence [4], with one third of students reporting that they experienced cyberbullying for the first time while at college [5]. For university students, cyberbullying has been associated with missing class, reduction in grades, suicidal ideation [6], and for female university students with depression [7] and antisocial behavior [8].

Estimates of the percentage of university students who have been victims of cyberbullying range from low $(10$ to $15 \%[9,10])$, to medium (24 to $62 \%$ [6,11-14]), to as high as $92 \%$ [15]. The prevalence of cyberbullying perpetration is reportedly lower (e.g. $2 \%$ [14], $8 \%$ $[6,12,14], 23 \%[11]$, and $40 \%[13])$.

The variability in prevalence rates could be due to differences in definitions of cyberbullying, and the use of differing measures. When asked directly if they had been cyberbullied prevalence was only around $11 \%$, whereas over $30 \%$ reported experiencing undesireable or obsessive communication [10]. Prevalence rates are lower when researchers include a definition of cyberbullying [16], and, in a metaanalysis of 80 studies [17], using the term "bully" was found to lower prevalence rates.

Due to the problems with differing definitions of cyberbullying and the varied measures used to survey prevalence rates, Doane et al. [18] developed a multifactor cyberbullying victimization and perpetration questionnaire, the Cyberbullying Experiences Survey (CES), for use with an emerging adult population. An operational definition of cyberbullying was deliberately omitted, with the questions instead focussing on cyberbullying behaviors. The questionnaire was completed by 638 students of psychology at a large university in the United States, and the researchers found that $96 \%$ of respondents had been a victim of some form of cyberbullying, and $84 \%$ had perpetrated cyberbullying behaviors, at least once in the last year.The CES was shown to be internally consistent and had good convergent validity $[1,19]$.

Of the small amount of recent research on cyberbullying in New Zealand, most has focussed on the adolescent age group [2022]. Therefore, we aimed to replicate Doane et al.s [18] study with psychology students at a New Zealand university.

\section{Methods}

\section{Respondents}

Psychology students at the University of Waikato were invited to complete the CES, but the questionnaire was open to all students. Our final convenience sample was 312 students, $76 \%$ female, $76 \%$ were psychology students with a mean age of 22.8 years (95\% CI [22.0, 23.6]). Most were European or Pākehā (72\%), and Māori (14\%), with the remainder being Asian (7.6\%), Pasifika (4.0\%), or Middle Eastern/ Latin American/African (1.6\%). Most were undergraduate students (95\%), with $40 \%$ first-year, $24 \%$ second-year, $31 \%$ third-year students and $5 \%$ were graduate students. The composition of our sample closely matched Doane et al.s [18].

\section{Materials}

We replicated the CES in Qualtrics ${ }^{\circledR}$ and respondents accessed the survey online via a personal computer or mobile device. Doane et al. [18] listed all survey items in their Tables 4 and 6 (p. 212 and 213) and

"Corresponding Author: Dr. Rebecca J. Sargisson, School of Psychology, The University of Waikato, Private Bag 12027, Tauranga 3112, New Zealand, Tel: +64 78379580; E-mail: sargisson@waikato.ac.nz

Citation: Phizacklea T, Sargisson RJ (2018) The Cyberbullying Experiences Survey with New Zealand Psychology Students. Int J Psychol Behav Anal 4: 146. doi: https://doi.org/10.15344/2455-3867/2018/146

Copyright: (C) 2018 Sargisson et al. This is an open-access article distributed under the terms of the Creative Commons Attribution License, which permits unrestricted use, distribution, and reproduction in any medium, provided the original author and source are credited. 
Citation: Phizacklea T, Sargisson RJ (2018) The Cyberbullying Experiences Survey with New Zealand Psychology Students. Int J Psychol Behav Anal 4: 146. doi: https://doi.org/10.15344/2455-3867/2018/146

Page 2 of 6

we used these same items. We randomised the question order within each scale for each respondent.

\section{Procedure}

Respondents answered questions regarding the frequency of behaviors experienced or perpetrated via electronic means in the past year on a 6-point Likert scale. Response options were: never (0), less than a few times a year (1), a few times a year (2), once or twice a month (3), once or twice a week (4), and every day/almost every day (5). Respondents were advised that "electronic" refers to any communication through internet, cell phone text messaging cell phone picture messaging, cell phone Internet browsing, and Blackberry, or similar types of devices. We received ethics approval from the Psychology Research and Ethics Committee, \#15:15 under the delegated authority of the University of Waikato Human Research Ethics Committee.

\section{Data Analysis}

Of the 312 respondents who completed the CES, eight did not complete all of the questions in the perpetration section of the questionnaire. Where a response was not recorded for any question for any respondent, that cell was left blank.

\section{Results}

When asked how often they accessed social media, $62.6 \%$ of respondents reported several times a day, $27.9 \%$ daily, $4.6 \%$ weekly, $2.6 \%$ a few times a month or less, and $2.3 \%$ never. Overall, $94.9 \%(100 \%$ of men and $93.1 \%$ of women) reported that they had experienced some form of cyberbullying in the past year. Overall, $82.0 \%$ (86.1\% of men and $80.7 \%$ of women) reported that they had perpetrated some form of cyberbullying in the past year.

The percentage of respondents who had experienced or perpetrated cyberbullying using the criteria of any occurrence higher than zero in a year was extremely high. Therefore, we also calculated the average scale score across the 21 victimization and 20 perpetration items, where 0 indicates that the respondent never experienced or perpetrated these behaviors in the last year, and 5 indicates that they experienced or perpetrated them daily, or almost every day. The mean of each respondents' average victimization score was 0.73 (95\%
CI $[0.66,0.80])$, which corresponds most closely to the option "Less than a few times a year". The mean of the average perpetration scores was 0.37 (95\% CI [0.31,0.42]), which corresponds most closely to the option "Never".

To allow direct comparison to the findings of Doane et al. [18], we conducted independent $t$ tests using mean scale scores to examine the potential influence of gender on victimization and perpetration, as well as on each of the four factors in both cases; public humiliation, malice, deception, and unwanted contact.

As shown in Table 1, men reported experiencing significantly more victimization than women, $t(107)=2.35, p=.02, \hat{d}=.33$, and, in particular, more malice, $t(97)=4.01, p<.001, \hat{d}=.62$, and deception, $t(301)=2.08, p=.04, \hat{d}=.28$. No significant differences were found for public humiliation, $t(101)=1.43, p=.16, \hat{d}=.20$, or unwanted contact, $t(301)=-1.01, p=.31, \hat{d}=-.15$, although the mean score for unwanted contact was the only score higher for women than for men.

Men reported perpetrating cyberbullying significantly more than women overall, $t(79)=5.04, p<.001, \hat{d}=0.99$, and for all four perpetration factors; public humiliation, $t(82)=2.48, p=.02, \hat{d}=.46$, malice, $t(81)=5.54, p<.001, \hat{d}=1.02$, deception, $t(81)=3.10, p=.003$, $\hat{d}=0.57$, and unwanted contact, $t(76)=3.22, p=.002, \hat{d}=0.67$.

As shown in Table 2, significant positive correlations $(p<.01)$ were found for scores in all factor groupings ( $r$ values varied between .27 and .70), such that high scores on any one of the four factors were associated with high scores for all other factors for both victimization and perpetration. Particularly high correlations were found between perpetrated and victimized malice, $r(303)=.70$, suggesting that victims of malice are also likely to be perpetrators of malice, victimization for public humiliation and deception, $r(310)=.70$, and for malice and deception, $r(310)=.68$, suggesting that victims of cyberbullying are more likely to experience several types of bullying.

We coded the data such that any respondent with a mean victimization score greater than one and a mean perpetration score greater than 0.8 was coded as being both a victim and a perpetrator (a bully-victim) of cyberbullying. Of 305 respondents, we classified 28 as bully-victims; 17 of 72 men and 11 of 233 women. Men were 6 times more likely than women to be bully-victims, $\chi^{2}(1)=23.54, p<.001, \Phi$ $=.28$. Respondents who were both victims and perpetrators did not differ in terms of age from those who were not, $t(301)=.18, p=.86$.

\begin{tabular}{|l|c|c|c|c|c|}
\hline & & & & \multicolumn{2}{|c|}{$95 \%$ CIs (MD) } \\
\hline Factor & Men $(\mathrm{M})$ & Women $(\mathrm{M})$ & Mean Difference(MD) & Lower Limit & Upper Limit \\
\hline Victimization & 0.89 & 0.68 & 0.22 & 0.04 & 0.39 \\
\hline Public humiliation & 0.48 & 0.39 & 0.10 & -0.02 & 0.22 \\
\hline Malice & 1.85 & 1.16 & 0.69 & 0.35 & 0.01 \\
\hline Deception & 0.93 & 0.71 & 0.22 & -0.36 & 0.11 \\
\hline Unwanted contact & 0.58 & 0.71 & -0.12 & 0.25 & 0.58 \\
\hline Perpetration & 0.69 & 0.27 & 0.42 & 0.05 & 0.43 \\
\hline Public humiliation & 0.48 & 0.24 & 0.24 & 0.55 & 1.17 \\
\hline Malice & 1.41 & 0.57 & 0.86 & 0.11 & 0.49 \\
\hline Deception & 0.51 & 0.22 & 0.30 & 0.08 & 0.32 \\
\hline Unwanted contact & 0.27 & 0.07 & 0.20 & 0.43 \\
\hline
\end{tabular}

Table 1: Mean Scores for Factor Responses and Gender Differences in the Victimization and Perpetration Scales.

Note. Confidence intervals that do not contain 0 indicate significance at the $\alpha=0.05$ level. 
Citation: Phizacklea T, Sargisson RJ (2018) The Cyberbullying Experiences Survey with New Zealand Psychology Students. Int J Psychol Behav Anal 4: 146. doi: https://doi.org/10.15344/2455-3867/2018/146

Page 3 of 6

We conducted a mixed multivariate analysis of variance (MANOVA) using gender (between-subjects) and victimization vs. perpetration (within-subjects) as independent variables and the mean scale scores for each of the four factors to investigate possible interactions between gender and victimization/perpetration.

As with the t tests, the MANOVA showed a similar significant main effect of gender. There was also a significant main effect of the factor victimization/perpetration. Respondents were significantly more likely to be victims of cyberbullying (means and CIs already given) than perpetrators, independently of gender, $V=.31, F(4,298)=33.19$, $p<.001$, with mean victimization scores being significantly higher than perpetration scores for all four factors: Public Humiliation, $F(1$, $301)=4.62, p=.03 ;$ Malice $F(1,301)=80.13, p<.001 ;$ Deception, $F(1$, $301)=91.31, p<.001 ;$ Unwanted contact, $F(1,301)=73.03, p<.001$
The MANOVA also showed a significant interaction between gender and victimization and perpetration scales, $V=.04, F(4,298)$ $=3.06, p=.02$. As shown in Figure 1, it appears that: While men and women are equally likely to be victims of public humiliation, women are less likely than men to publicly humiliate others, $F(1,301)=4.75$, $p=.03$. There was no interaction for malice or deception, $F(1,301)=$ $2.20, p=.14, F(1,301)=.60, p=.44$, in that both men and women experienced malice and deception more than they perpetrated it, with men being overall more likely to both experience and perpetrate. Respondents were more likely to be victims of unwanted contact than perpetrators, but women were more likely to be victims than men, and less likely to be perpetrators, $F(1,301)=8.51, p=.004$. Please note that the data for the MANOVA violated Box's M assumption of equality of covariance matrices, so significant differences should be treated with caution.

\begin{tabular}{|c|c|c|c|c|c|c|c|c|c|}
\hline & \multicolumn{4}{|c|}{ Victimization } & \multicolumn{4}{|c|}{ Perpetration } \\
\hline & & $\mathrm{PH}$ & $\mathrm{M}$ & $\mathrm{D}$ & UC & $\mathrm{PH}$ & $\mathrm{M}$ & $\mathrm{D}$ & UC \\
\hline \multirow[t]{4}{*}{ Victimization } & $\mathrm{PH}$ & 1 & .67 & .70 & .57 & .52 & .46 & .45 & .42 \\
\hline & M & & & .68 & .57 & .44 & .70 & .39 & .39 \\
\hline & $\mathrm{D}$ & & & & .63 & .43 & .49 & .49 & .47 \\
\hline & UC & & & & & .31 & .32 & .27 & .37 \\
\hline \multirow[t]{4}{*}{ Perpetration } & $\mathrm{PH}$ & & & & & & .57 & .60 & .60 \\
\hline & M & & & & & & & .55 & .46 \\
\hline & $\mathrm{D}$ & & & & & & & & .65 \\
\hline & UC & & & & & & & & 1 \\
\hline
\end{tabular}

Table 2: Correlations among Factors for Victimization and Perpetration ( $\mathrm{PH}=$ Public Humiliation, $\mathrm{M}=\mathrm{Malice}, \mathrm{D}=$ Deception, and UC = Unwanted Contact).

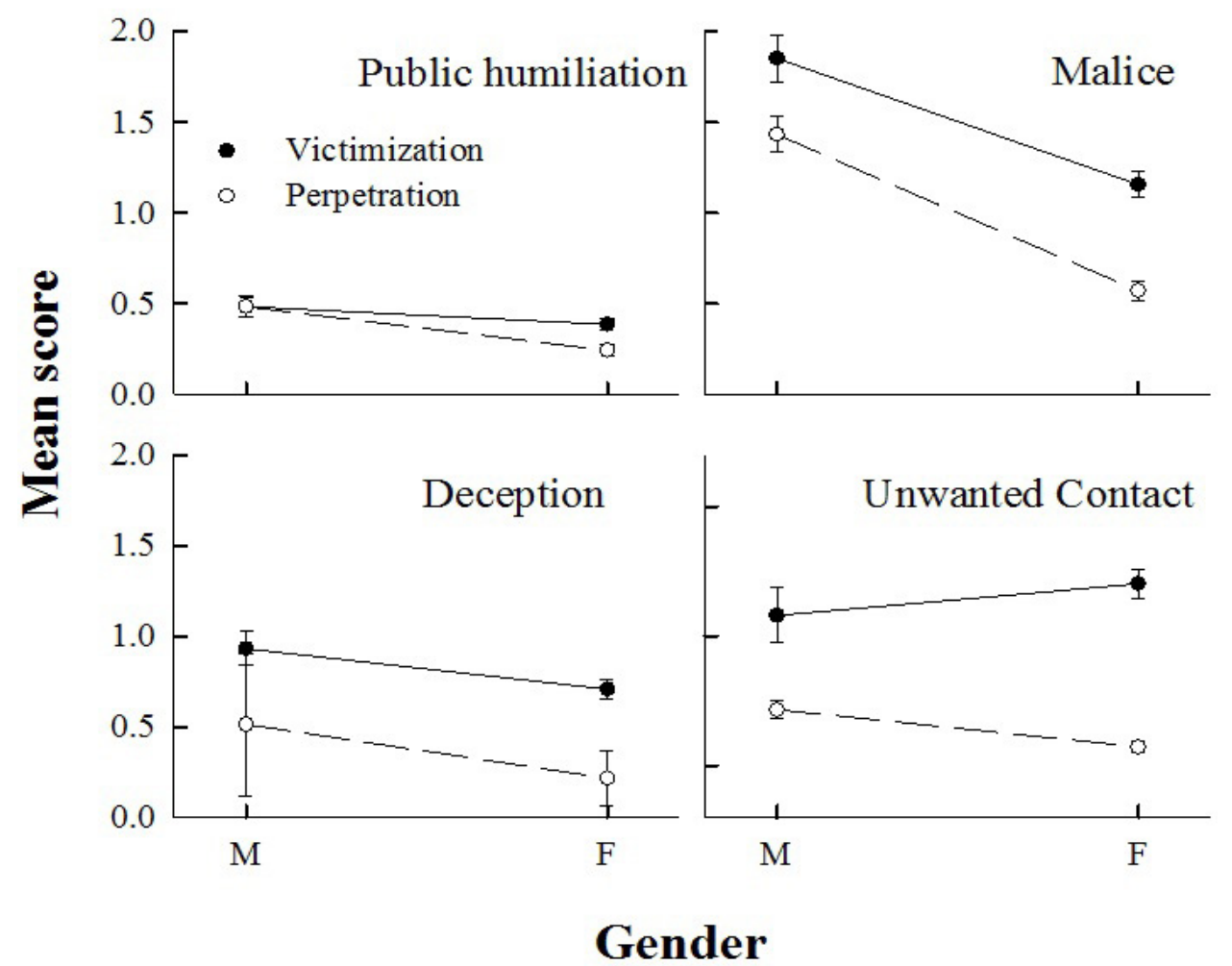

Figure 1: Mean score $(0$ - 5) for men and women for the four factors for victimization (solid lines) and perpetration (dashed lines). Error bars show standard error of the mean. 


\section{Reliability}

Cronbach's alpha for overall scale reliability was .95, 95\% CI [.94, .96], and would not be improved by removing any individual items. Cronbach's alpha values for each factor for both victimization and perpetration were close to or above .70 , ranged from excellent to acceptable, and are compared with the values obtained by Doane et al. [18] in Table 3.

\begin{tabular}{|l|l|l|l|l|}
\hline \multicolumn{5}{|c|}{ Doane et al. [16] } \\
\hline Factor & Items & $\alpha$ & $\alpha$ & $95 \%$ CI \\
\hline Victimization & $\alpha$ & .89 & 0.80 & {$[.76, .83]$} \\
\hline 1. Public Humiliation & 9 & .87 & 0.92 & {$[.90, .93]$} \\
\hline 2. Malice & 5 & .84 & 0.87 & {$[.84, .89]$} \\
\hline 3. Unwanted Contact & 4 & .74 & 0.71 & {$[.65, .76]$} \\
\hline 4. Deception & 3 & .94 & 0.83 & {$[.80, .86]$} \\
\hline Perpetration & \multicolumn{5}{|l|}{} \\
\hline 1. Unwanted Contact & 8 & .90 & 0.90 & {$[.88, .92]$} \\
\hline 2. Malice & 6 & .83 & 0.73 & {$[.67, .78]$} \\
\hline 3. Public Humiliation & 3 & .83 & 0.69 & {$[.62, .74]$} \\
\hline 4. Deception & 3 &
\end{tabular}

Table 3: Cronbach's Alpha ( $\alpha$ ) from Doane et al. [18] and from our Study (with Confidence Intervals) for Each Factor for Victimization and Perpetration

\section{Discussion}

The majority of our respondents reported having had experienced (94.9\%) and perpetrated (82.0\%) cyberbullying behaviors in the past year. These prevalence rates for New Zealand University students of psychology are comparable to those of tertiary students of psychology in the US found for victimization (96.1\%) and perpetration (84.2\%) using the same scale (the CES) [18].

Overall victimization and perpetration rates, both for our study and Doane et al.'s [18] are higher than those for some previous studies $[6,9,10-12,14]$, possibly due to definition differences, the advancing of technology types, and increased internet usage. Some researchers have reported that New Zealand school students are bullied at higher rates than the international average [23,24], however, so perhaps our high prevalence rate here reflects that a higher-than-average rate of cyberbullying is present in New Zealand.

In meta-analyses, researchers who provided an operational definition of cyberbullying, or used the term "(cyber) bully" within their questionnaire, yielded lower prevalence rates than those who only described cyberbullying behaviors $[16,17]$. Unlike some researchers [6,9-11], but similar to others $[12,14,18]$, we did not give a definition of cyberbullying, nor did any questions use the word "bully" or "cyberbully". Including a definition may result in underestimation of cyberbullying due to the respondents' lack of awareness of [12], or confusion regarding [25], the behaviors that constitute cyberbullying, or because the word "bully" has negative connotations which respondents do not associate with their online activity [17]. Bennett et al.'s [15] prevelance rates for victimization (92\%), which were similar to ours, support this conclusion, as their survey instrument also focussed on counting specified behaviors, rather than preconceived conceptions of cyberbullying held by participants.
The CES does not limit the medium by which respondents may have experienced cyberbullying, instead providing examples of hardware through which cyberbullying could have taken place. Prevalence rates may be underestimated in research focused specifically on e-mail and instant messaging (e.g. [9]) and Slonje et al. [26] suggested that cyberbullying prevalence is increasing due to changes in technology.

Due to the high prevalence rates we found using the criteria of at least one instance in the last year, we also analysed data using the mean scale scores, which might also be thought of as a measure of the frequency with which cyberbullying behaviors are experienced and perpetrated. Similar to Akbulut and Eristi [27], we found that while our prevalence rates were high, the mean prevalence rates were rather low. These results suggest that there is value in exploring the analysis of cyberbullying data, as different ways of calculating scores may lead to vastly different estimates of prevalence.

An advantage of the CES is the ability to analyse the frequency of different types of cyberbullying behavior [18]. Langos [28] studied the potential harm caused by various forms of cyberbullying and suggests that the harm caused depends on the ferocity and frequency of the behaviors which, whilst hurtful, may not necessarily cause serious harm. Smith et al. [29] point out that some forms of teasing can be considered prosocial, and are intended to be friendly and playful. However, interpreting teasing as prosocial requires contextual cues, such as a friendly tone of voice [29], which may be absent in electronic forms of communication. Thus, research should investigate how online behavior is perceived by the receiver in order to determine its potential harmfulness.

Unwanted contact was the only form of cyberbullying behaviour that the women in our sample reported experiencing at higher frequencies than men did (Table 1). These results were similar to those of Marsh et al. [30] with a sample of New Zealand secondary-school students, suggesting that patterns begun at younger ages continue into higher education. The victimization questions for unwanted contact include such things as receiving unwanted sexual messages, and nude or offensive photos, and these behaviours were almost exclusively perpetrated by men. A recent study [31] also reported that the non-consensual sharing of images, typically containing sexually explicit material, was a major concern for female university students. Emerging adults are often involved in unstable off-and-on romantic relationships characterised by physical violence and verbal abuse [32]. Inexperience with intimate relationships might contribute to cyberbullying in this population in that intimate aggression may be perpetrated in cyberspace through stalking, posting incriminating photos, and sending harassing text messages [33]. There is some evidence from a sample of young adults that unwanted cyber-contact is a more intentional behaviour than malice [34], and in Crosslin and Golam's [35] study, $30 \%$ of the university students reported that cyberbullying is used by friends and ex-partners to harm romantic relationships and $21 \%$ to retaliate when relationships break down. Unwanted-contact behaviors have the potential to cause serious harm [28], and the female college students who had the highest odds of being diagnosed with depression in one study were those who experienced unwanted sexual advances [7].

Deceptive behaviours were experienced fairly frequently by our respondents (Table 1). There are several types of deception possible on the internet [36], deception is easier on the internet due to the increased anonymity of the users [37], and people are more likely to lie about themselves, rather than about others, when communication 
Citation: Phizacklea T, Sargisson RJ (2018) The Cyberbullying Experiences Survey with New Zealand Psychology Students. Int J Psychol Behav Anal 4: 146. doi: https://doi.org/10.15344/2455-3867/2018/146

Page 5 of 6

is computer-mediated compared to face-to-face [38]. Wright [39] found that a belief that their actions were anonymous was positively related to cyber-aggression for the young adults in her study, as was the belief that online material is not permanent. Some of the possible deceptive internet behaviors include gender switching, age deception, enhancement of status, and impersonation [36]. Few researchers have investigated the effects of online deception on victims [37]. In our study, however, we were unable to specify the nature of the deception given the generality of the wording of the question "Has someone lied about themselves to you electronically". Therefore, it is difficult to ascertain the motivation of the sender, the impact of the deception on the receiver, or whether the receiver knew the sender of the message. Respondents under 30 years old were more likely to engage in frequent deception online than those over 30 years old [40], and, according to Caspi and Gorsky's [40] participants, the primary motivations for lying about themselves online was to preserve their privacy and safety or to 'play' with their identity rather due to any malicious intent. Thus, the behaviors described in the questions in the CES relating to deception may or may not constitute cyberbullying and more research is required on internet deception and its relationship with bullying.

Some researchers have found no gender difference amongst university students in perpetration and victimization of cyberbullying $[5,9,10]$, and at least one has reported higher rates of victimization for women [11]. Our results support those who have found higher rates of cyberbullying victimization $[6,12,15,18,41]$ and perpetration $[11,12,15,18,41]$ for male university students compared to female. Our data aligns with data from studies of traditional bullying with secondary-school students [42] that men were more likely than women to be both victims and perpetrators of cyberbullying. For traditional bullying, secondary-school students who are bullyvictims show poorer psychosocial functioning than bullies, who, in turn, display poorer functioning than victims [43], which suggests that cyber-bully-victims warrant further research to determine the characteristics of this group, as well as the antecedents and the potential consequences of their bullying behaviour in the context of their also being victims.

A limitation of our study is the self-report nature of survey design in which social desirability bias is a risk, potentially altering prevalence rates. Sargisson and McLean [44] point out that self-reported behavior may not accurately reflect actual behavior, however, this limitation is shared by other research using questionnaires, which currently constitutes much of the literature on cyberbullying. Future researchers could attempt to measure the prevalence of cyberbullying in other ways to avoid the social desirability bias, such as through content analyses of online exchanges, or through experimental studies.

We used a convenience sample of psychology students at a single university in New Zealand, over-represented by women. While this limits the generalizability of our results, the composition of our sample was very similar to that of Doaneet al. [18], and therefore a fair replication of their study in a different country. Future researchers should seek to expand their populations, and use random sampling methods to improve generalizability.

\section{Conclusion}

It is apparent that cyberbullying remains a problem in the emerging adult population. Further research is needed in this relatively new area of investigation to fully understand the nature of cyberbullying with an aim to reduce its prevalence and mitigate its effects.
Our investigation adds to the growing body of literature on the prevalence of cyberbullying behaviors, and gender differences, amongst university students.

\section{Competing Interests}

The authors declare that they have no competing interests.

\section{References}

1. Hinduja S, Patchin JW (2009) Bullying beyond the schoolyard: Preventing and responding to cyberbullying. Thousand Oaks CA: Corwin Press.

2. Hoff DL, Mitchell SN (2008) Cyberbullying: Causes, effects, and remedies. $\mathrm{J}$ of Educ Admin 47: 652-665.

3. Aricak OT (2009) Psychiatric symptomatology as a predictor of cyberbullying among university students. Eurasian $\mathrm{J}$ of Edu Res 34: 167-184.

4. Tsitsika A, Janikian M, Wójcik S, Makaruk K, Tzavela E, et al. (2015) Cyberbullying victimzation prevalence and associations with internalising and externalising problems among adolescents in six European countries. Comp in Human Behavior 51: 1-7.

5. Kowalski RM, Giumetti GW, Schroeder AN, Reese HH (2012) Cyber bullying among college students: Evidence from multiple domains of college life. In: Wankel LA, Wankel C, eds. Misbehavior online in higher education. EGP 5: 293-321.

6. Faucher C, Jackson M, Cassidy W (2014) Cyberbullying among university students: Gendered experiences, impacts, and perspectives. Edu Res Int.

7. Selkie EM, Kota R, Chan YF, Moreno M (2015) Cyberbullying, depression, and problem alcohol use in female college students: A multisite study. Cyberpsychol Behav Soc Netw 18: 79-86.

8. Sargent KS, Krauss A, Jouriles EN, McDonald R (2016) Cyber victimization, psychological intimate partner violence, and problematic mental health outcomes among first-year college students. Cyberpsychol Behav Soc Netw 19: 545-550.

9. Finn J (2004) A Survey of Online Harassment at a university campus. J Interpers Violence 19: 468-483.

10. Walker CM, Sockman BR, Koehn S (2011) An exploratory study of cyberbullying with undergraduate university students. TechTrends 55: 3138.

11. Dilmaç B (2009) Psychological needs as a predictor of cyber bullying: A preliminary reporton college students. Educational Sciences: Theory \& Practice 9: 1307-1325.

12. Francisco SM, Simão AMV, Ferreira PC, das Dores Martins MJ (2015) Cyberbullying: The hidden side of college students. Comp in Human Behavior 43: 167-82

13. Zhang AT, Land LPW, Dick, G (2010) Key Influences of Cyberbullying for University Students. In: PACIS 2010 Proceedings.

14. Blaya C, Kaur K, Sandhu D, Sundaraam S (2018) Cyberbullying in higher education in India and France. In PK Smith, S Sundaram, BA Spears, C Blaya, M Schafer \& D Sandhu (Eds.), Bullying, cyberbullying and student well-being in schools. Cambridge, Cambridge University Press.

15. Bennett DC, Guran EL, Ramos MC, Margolin G (2011) College students' electronic victimization in friendships and dating relationships: Anticipated distress and associations with risky behaviors. Violence Vict 26: 410-429.

16. Ybarra ML, Boyd D, Korchmaros JD, Oppenheim JK (2011) Defining and measuring cyberbullying within the larger context of bullying victimization. J Adolesc Health 51: 53-58.

17. Modecki KL, Minchin J, Harbaugh AG, Guerra NG, Runions KC (2014) Bullying prevalence across contexts: A meta-analysis measuring cyber and traditional bullying. J Adolesc Health 55: 602-611.

18. Doane AN, Kelley ML, Chiang ES, Padilla MA. Development of the Cyberbullying Experiences Survey. Emerging Adulthood2013;1: 207-18.

19. Ybarra ML, Diener-West M, Leaf PJ (2007) Examining the overlap in Internet harassment and school bullying: Implications for school intervention. $J$ Adolesc Health.

20. Fenaughty J, Harre N (2013) Factors associated with distressing electronic harassment and cyberbullying. Comp in Human Behavior 29: 803-811. 
Citation: Phizacklea T, Sargisson RJ (2018) The Cyberbullying Experiences Survey with New Zealand Psychology Students. Int J Psychol Behav Anal 4: 146. doi: https://doi.org/10.15344/2455-3867/2018/146

21. Jose PE, Kljakovic SE, Scheib E, Notter O (2012) The joint development of traditional bullying and victimization with cyber bullying and victimization in adolescence. J Res Adolesc 22:301-309.

22. Raskauskas $J$ (2009) Text-bullying: Associations with traditional bullying and depression among New Zealand adolescents. J School Violence 9: 74-97.

23. Raskauskas J, Prochnow JE (2007) Text-bullying in New Zealand: A mobile twist on tradictional bullying. New Zealand Annual Review of Education 16 89-104.

24. Kljakovic M, Hunt C, Jose PE (2015) Incidence of bullying and victimisation among adolescents in New Zealand. New Zealand Journal of Psychology 44: $57-67$.

25. Kowalski RM, Giumetti GW, Schroeder AN, Lattanner MR (2014) Bullying in the digital age: A critical review and meta-analysis of cyberbullying research among youth. Psychol Bull 140: 1073-1137.

26. Slonje R, Smith PK, Frisén A (2013) The nature of cyberbullying, and strategies for prevention. Computers in Human Behavior 29: 26-32.

27. Akbulut $Y$, Eristi $B$ (2011) Cyberbullying and victimisation among Turkish university students. AJET 27: 1155-1170.

28. Langos C (2015) Cyberbullying: The Shades of Harm. Psychiatry, Psychology and Law 22: 106-123.

29. Smith H, Varjas K, Meyers J, Marshall ML, Ruffner C, et al. (2010) Teachers perceptions of teasing in schools. Journal of School Violence 9: 2-22.

30. Marsh L, McGee R, Nada-Raja S, Williams S (2010) Brief report: Text bullygin and traditional bullying among New Zealand secondary school students. J Adolesc 33: 237-240.

31. Mishna F, Regehr C, Lacombe-Duncan A, Daciuk J, Fearing G, et al. (2018) Social media, cyber-aggression and student mental health on a university campus. J Ment Health 27: 222-229.

32. Halpern-Meekin S, Manning WD, Giordano PC, Longmore MA (2013) Relationship churning, physical violence, and verbal abuse in young adult relationships. J Marriage Fam 75: 2-12.

33. Melander LA (2010) College students' perceptions of intimate partner cyber harassment. Cyberpsychol Behav Soc Netw 13: 263-268.

34. Doane AN, Pearson MR, Kelley ML (2014) Predictors of cyberbullying perpetration among college students: An application of the Theory of Reasoned Action. Comput Human Behav 36: 154-162.

35. Crosslin K, Golman, M (2014) Maybe you don't want to face it-College students' perspectives on cyberbullying. Comput Human Behav 41: 14-20.

36. Utz S (2005) Types of decpetion and underlying motivation: What people think. Soc Sci Comput Rev 23: 49-56.

37. Stieger S, Eichinger T, Honeder B (2009) Can mate choice strategies explain sex differences? The deceived persons' feelings in reaction to revealed online deception of sex, age, and appearance. Social Psychology 40: 16-25.

38. Zimbler M, Feldman RS (2011) Liar, liar, hard drive on fire: How media context affects lying behavior. J Appl Soc Psychol 41: 2492-507.

39. Wright MF (2013) The relationship between young adults' beliefs about anonymity and subsequent cyber aggression. Cyberpsychol Behav Soc Netw 16: 858-862.

40. Caspi A, Gorsky P (2006) Online deception: Prevalence, motivation, and emotion. Cyberpsychol Behav 9: 54-59.

41. Kokkinos CM, Antoniadou N, Markos A (2014) Cyber-bullying: An investigation of the psychological profile of university student participants. J Appl Dev Psychol 35: 204-214.

42. Solberg ME, Olweus D, Endresen IM (2007) Bullies and victims at school: Are they the same pupils? Br J Educ Psychol 77: 441-464

43. Haynie DL, Nansel T, Eitel P, Crump AD, Saylor K, et al. (2001) Bullies, victims, and bully/victims: Distinct groups of at-risk youth. The Journal of Early Adolescence 21: 29-49.

44. Sargisson RJ, McLean IG (2015) Linking knowledge and action on sustainable living. Sustainability: The Journal of Record 8: 127-35. 